\title{
Festival Teatro a Corte Experiências e gestos
}

\section{Rita Martins}

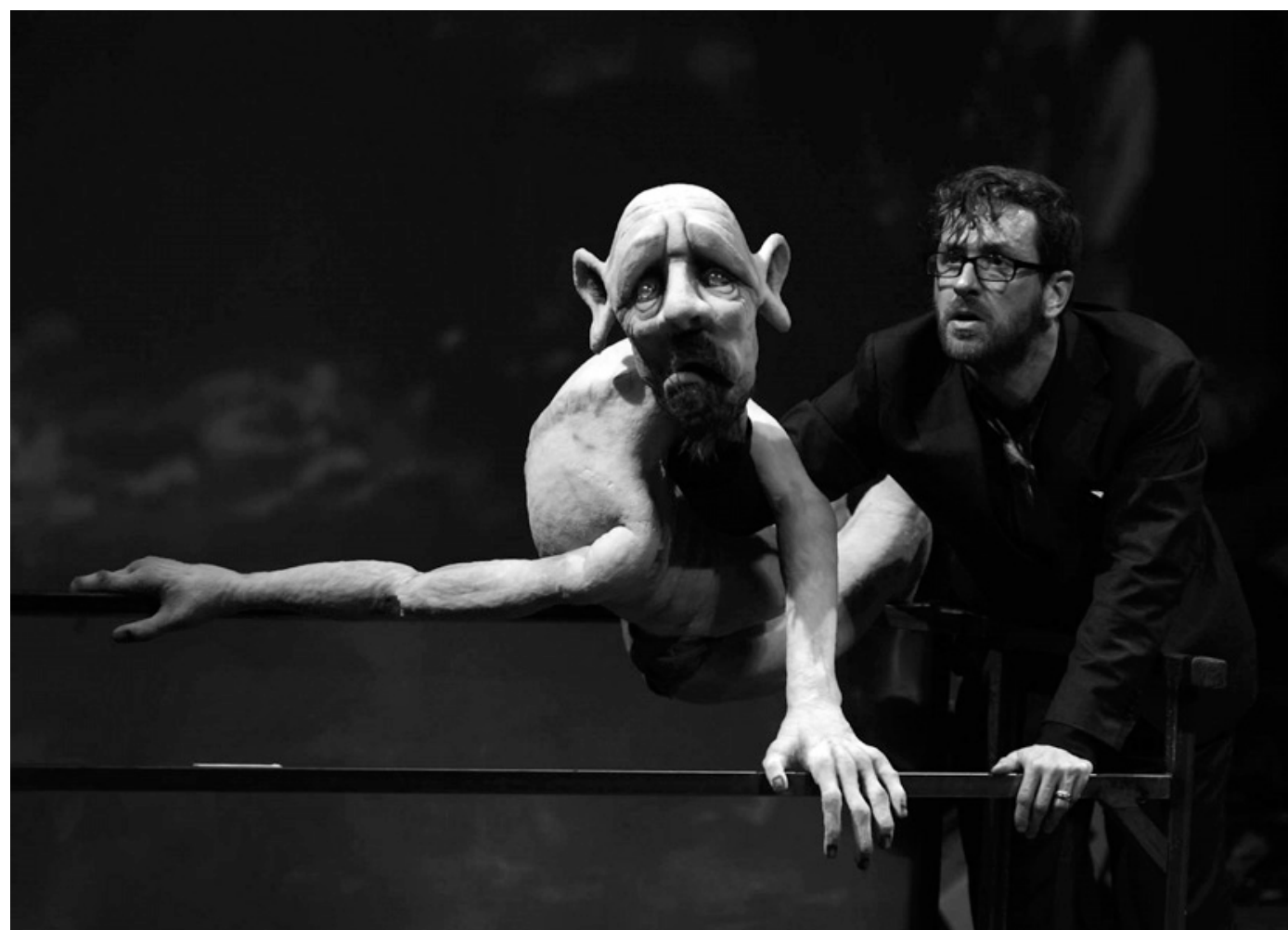

"Mais de cinquenta espectáculos, vinte dias de festa internacional, dez paises europeus", anunciava Beppe Navello no programa do Festival Teatro a Corte. Podiamos tratálo por Beppe, já que o persistente director das festividades turinenses, que celebraram este ano o seu décimo aniversário, era uma figura familiar: estava presente em todos os espectáculos e, como bom e orgulhoso anfitrião, apresentava as companhias e informava os espectadores sobre os acontecimentos do dia. 0 seu carinho pelo evento, que fundou em 2001 como Festival de Teatro Europeu, harmonizava-se com a delicadeza e eficiência dos elementos da organização que, entre 7 e 25 de Julho, receberam artistas, espectadores e jornalistas.

Em conversa amena pelas ruas do centro histórico de Turim, Sandro Avanzo, crítico de teatro e cinema em Milão, discorreu sobre a atmosfera "especial" do Teatro a Corte, factor que contribuiu para se converter num espectador assiduo e, também, num defensor do festival, cuja programação eclética, entre o teatro, a dança e o novo circo, nem sempre é reconhecida pelos críticos, tradicionalmente especializados em áreas restritas. Contrário a esta tendência, Avanzo é curador (com Laura Bevione) do livro comemorativo
Una storia. Dal festival Teatro Europeo al Festival Teatro a Corte, composto por artigos de análise de investigadores e testemunhos de artistas. Aos textos justapõem-se belíssimas fotografias dos espectáculos e, nos interstícios das palavras, trespassa esse fio dos afectos que faz do festival um acontecimento "especial" para os participantes.

De modo mais objectivo e informativo: em 2007, ano em que Beppe Navello assume a direcção da Fundação Teatro Piemonte Europa, a designação do festival mudou para Teatro a Corte, o que permitiu consolidar apoios e prolongar o espaço de intervenção à região de Piemonte. Mas a convicção de que o diálogo europeu começa na república das artes não esmoreceu com a alteração do nome e, nas palavras de Federica Mazzocchi, manteve-se a "vocação "excêntrica»" do festival, firmada na "abertura ao exterior e no valor da diversidade" (Mazzocchi 2011: 29, tradução minha). Se nos primeiros anos, a "abertura" se deu com o teatro a invadir o espaço urbano, as praças e ruas da cidade, agora estende-se aos castelos e palácios da antiga Casa de Sabóia. 0 alargamento das fronteiras traduz-se, ainda, nas opções de programação: uma multiplicidade de técnicas e géneros, sendo privilegiada
Rita Martins

é crítica de teatro investigadora do Centro de Estudos de Teatro da Faculdade de Letras, Universidade de Lisboa. Organizou em 2006 o livro Teatro completo, de D. João da Câmara, e publico em 2007 o estudo Rau Brandão: Do texto à cena, ambos editados pela Imprensa Nacional - Casa da Moeda. 
Murmúrios dos muros, de Victoria Thierree-Chaplin,

Compagnie des Petites Heures, Teatro Astra, 2011

(Aurelia Thierree),

fot. Lorenzo Passoni.

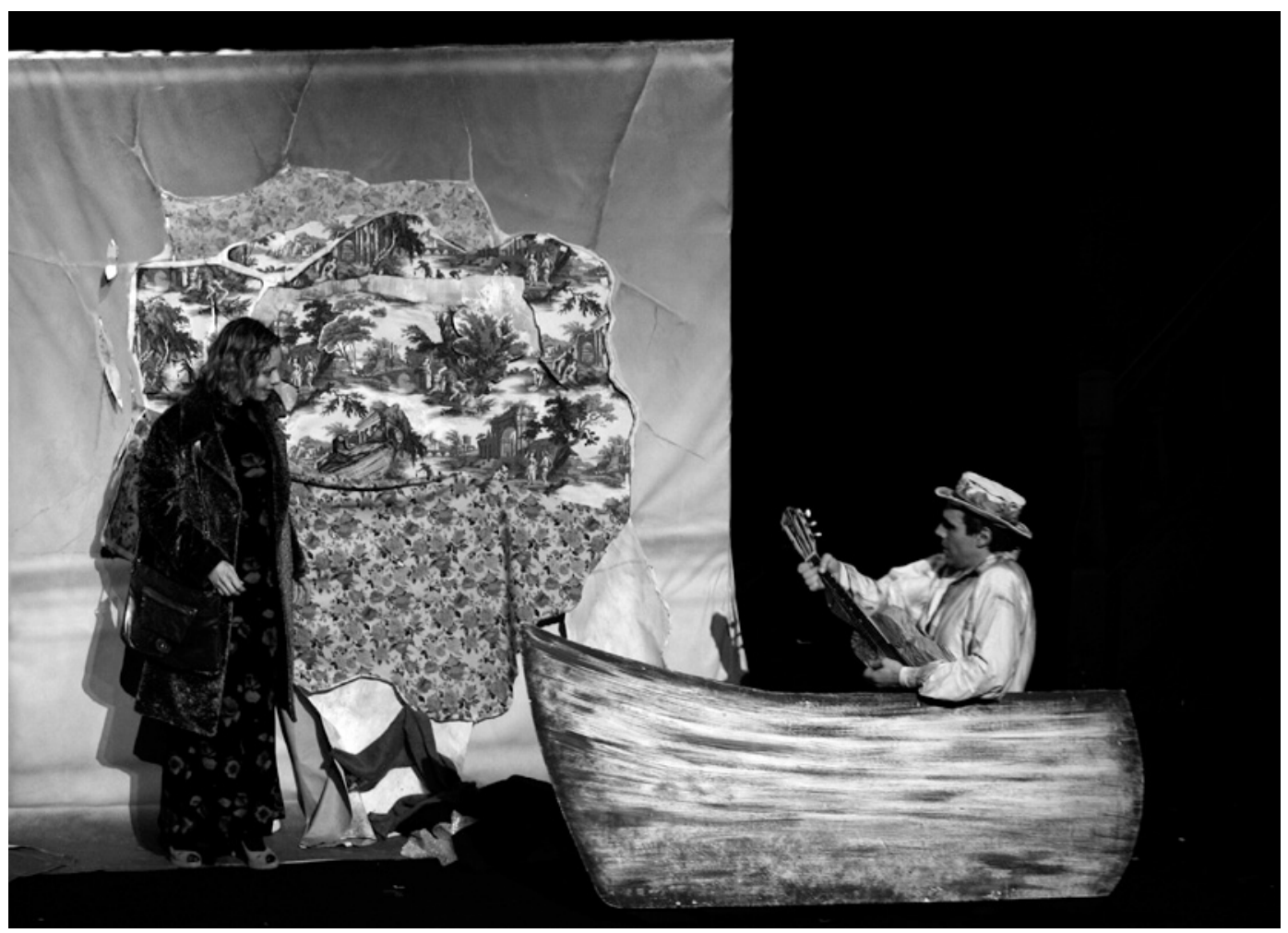

Interrupções continuas, cor. Olga Pona,

Teatro Dança

Contemporâneo de

Chelyabinsk,

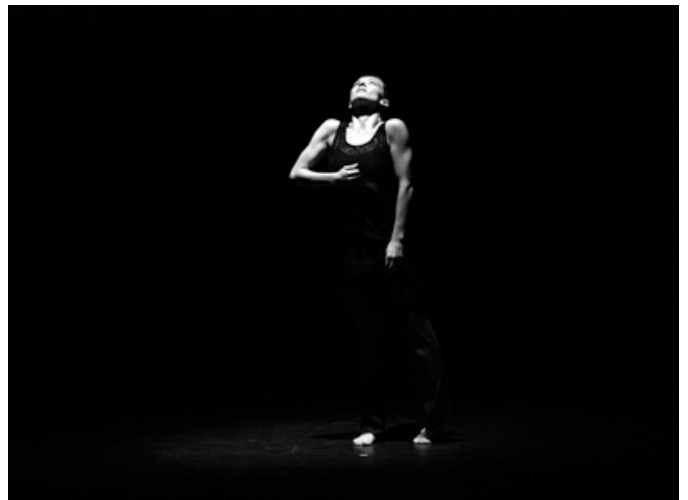

Ponto de fuga, de e com Stefano

Mazzotta, Emanuele

Sciannamea,

Evgeny Kulagin

Ivan Estegneev

Cie. Zerogrammi

Dialogue Dance, 2011

fot. Inna Glushenko

(fotografia de ensaio) a expressão não-verbal como forma de comunicação transnacional, entre artistas e espectadores.

0 primeiro fim-de-semana do festival foi

demonstrativo da sua especificidade, ou seja, da aposta nas formas híbridas, na experimentação e exploração de novas linguagens. Durante a tarde, nas duas salas da

Cavallerizza Reale, os espectadores puderam assistir aos espectáculos mais arrojados das Novas Sensibilidades e da Vitrina Russa, duas linhas de programação que deram a conhecer novos grupos (deste terceiro milénio), italianos e russos, fundados por jovens (e muito jovens) artistas.

As diferentes "sensibilidades" tiveram resultados dispares. Mimmo Conte e Carlotta Vitale, do Gommalacca Teatro, deram a provar 0 gosto da intimidade, um texto elaborado durante os ensaios pelos dois actores. Num registo tragicómico, seguimos o percurso de domesticação recíproca de um casal, desde o momento da sedução, numa festa, até ao homicídio, no sofá da sala. No extremo oposto da palavra, Helen Cerina, com formação em dança fez uma performance silenciosa intitulada Doces em Pomerio. Sentada frente a um balcão, Cerina edificava e destruía cidades feitas de cubos de açúcar, enquanto uma

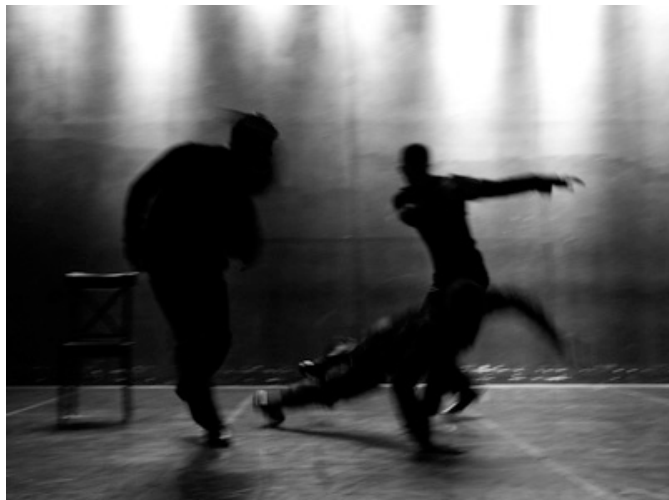

bailarina (Cláudia Giordano) rodopiava pelo espaço. As construções, progressivamente complexas, eram abatidas por gestos e sons infantis, repetindo-se o esquema previsivel e entediante. 0 trabalho "em progresso" foi justificado pela falta de financiamento de um dos produtores. Por essa razão, no final, a artista pediu o apoio dos espectadores para continuar a sua criação, mas não podemos deixar de registar o comentário de uma das espectadoras: "Pago para que parem."

E regressamos ao termo "especial", que, na minha opinião, caracteriza o Teatro a Corte - especial pelo acolhimento, especial pela vontade de oferecer um espaço de visibilidade aos jovens criadores, independentemente do prestígio e garantia de sucesso. Essa determinação prosseguiu na já mencionada Vitrina Russa do festival projecto inserido no programa de iniciativa governamenta Ano da Cultura e da Língua Italiana na Rússia e da Língua e da Cultura Russa em Itália. Mais uma vez, a dança contemporânea esteve em primeiro plano. Evgeny Kulagin e Ivan Estegneev, da Dialogue Dance (fundada em 2002), receberam em Kostroma, a norte de Moscovo, a Cie. Zerogrammi, fundada e constituída por Stefano Mazzotta 
e Emanuele Sciannamea em 2006. Estrearam Ponto de fuga, coreografia inspirada em Tieste de Séneca, onde o investimento no espaço começava com provocações belicosas e transformava-se em jogo de confronto entre os corpos. Quadrados pretos e brancos, delineados no chão pelos projectores de luz, organizavam o espaço geométrico e transmutável da luta, que terminou com uma alusão irónica aos másculos western spaghetti, acompanhada pela voz lânguida de Nancy Sinatra em Bang Bang. Tatiana Gordeeva e Evgeny Pankratov também alimentaram a ironia em Nova geometria, peça performática que tem como auto-referência a formação clássica de Tatiana. 0 humor e a resistência do corpo descobriramse em posições desconfortáveis, nos passos graciosos de bailado e na relação de equilibrio instável entre os corpos. Estes foram alguns dos espectáculos que decorreram durante as tardes quentes de início de Julho e que tiveram em comum a simplicidade de meios: mesas e cadeiras como objectos de apoio à dramaturgia do movimento, breves apontamentos sonoros ou musicais, o desenho de luz como principal recurso cénico para produção de atmosferas.

À noite, os grandes teatros abriram as portas a um público mais vasto. A coreógrafa russa, Olga Pona, trouxe os 13 bailarinos da sua companhia de Chelyabinsk ao belíssimo Teatro Carignano e o Teatro Astra encheu-se de espectadores para assistir ao Murmúrio dos muros, a mais recente encenação de Victoria Thierree-Chaplin, interpretada pela filha, Aurelia Thierree. Os muros, que dividem o visivel do invisivel, foram o pretexto para os telões pintados com casas ou para a aparição de figuras vivas, que escapavam da pintura de um papel de parede. Contudo, o encantamento prevaleceu sobre a construção dramatúrgica. Imagens extraídas ao sonho foram materializadas através de técnicas de prestidigitação e, sobretudo, de manipulação e transformação dos objectos em figuras insólitas. Um cavalo, feito de plástico de bolhas, que envolveu Aurelia num jogo de sedução, ou Aurelia dançando, suspensa no ar, constituíram momentos de um teatro visual dominado por um surrealismo onírico, envolto em melodias melancólicas. A beleza das imagens cativou o olhar, o engenho provocou o espanto.

0 Castelo de Moncalieri deveria ter sido o local de apresentação de leto, título do espectáculo e nome da companhia francesa de novo circo. Mas os imprevistos acontecem. As tempestades tropicais que se abateram sobre Turim obrigaram ao cancelamento de leto, enquanto Duda Paiva transitou para o teatro da Fonderie Limone Moncalieri com Bastard!, espectáculo inspirado muito livremente na obra de Boris Vian, 0 arranca corações. 0 bailarino e exímio manipulador de marionetas criou um pesadelo hilariante que principiou com uma extravagância surreal: um homem acorda numa lixeira com uma garrafa na mão e num pé a cabeça de um cavalo canta J'suis snob, de Vian. Duas marionetas vão amá-lo e atormentá-lo durante a viagem ao interior das suas obsessões e medos até à libertação. No final do espectáculo, convidados por Duda Paiva, os espectadores "atiraram-se" às figuras inanimadas, deixando o artista, ainda meio despido, a sorrir, num canto do palco. E este poderá ser o maior tributo do público, que se apaixonou por Clementine, a viciosa bailarina sem pernas, e o seu mórbido companheiro, cuja espuma maleável se fez imitação da humanidade.

E se falamos de humanidade, não posso deixar de lembrar o filme do dinamarquês Boris B. Bertram, Tankograd, que capta a sede de dançar dos bailarinos de Olga Pona. A preparação de um espectáculo sobre a leveza e a ausência de gravidade é mostrada, em simultâneo, com o documentário sobre as consequências do desastre nuclear de 1957, em Chelyabinsk, a cidade mais contaminada do mundo. 0 contraste é brutal e comovente. A ânsia de movimento e de harmonia, que tem os planetas como modelo ideal, convive com as doenças provocadas 
Nova geometria,

de Tatiana Gordeeva

e Evgeny Pankratov,

Cavallerizza Reale -

Manica Corta, 2011

(Tatiana Gordeeva, Evgeny

Pankratov).

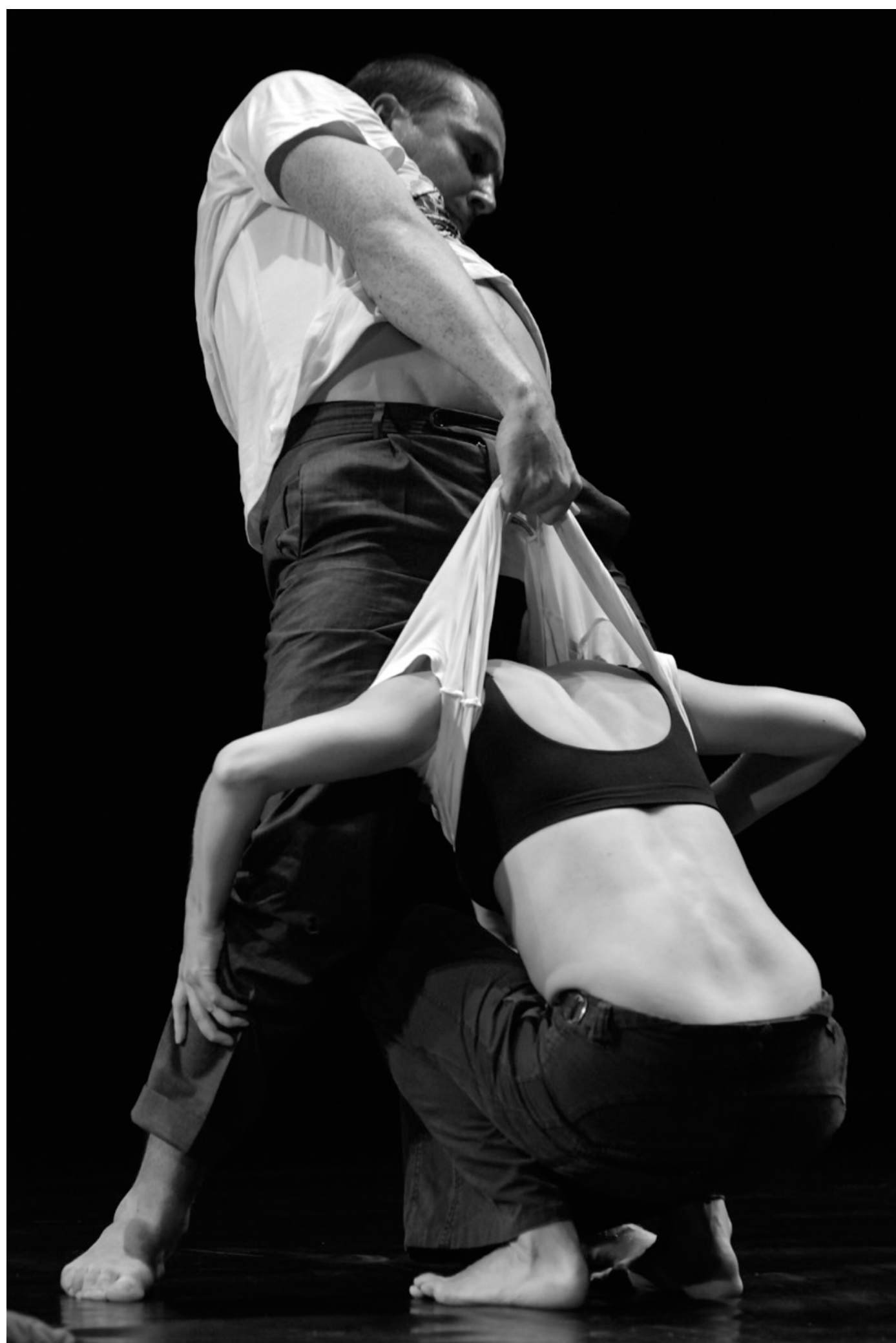

por radiações invisiveis que envenenam tudo o que é vivo

Referência bibliográfica

e permite a vida - o ar, a água, a terra.

Num ano de crise económica e de cortes orçamentais que atingiram as artes do espectáculo, Teatro a Corte fo um exemplo de produção: mostrou ter a paixão dos bailarinos russos, a imaginação da família Thierree, a criatividade de Duda Paiva, a vontade dos jovens que iniciam um percurso artístico, apesar das adversidades.
MAZZOCCHI, Federica (2011), "La vocazione "eccentrica" del Festival. Mimi, pagliacci, cavalli, artisti di strada e altro ancora", in Una Storia, Dal festival Teatro Europeo al festival Teatro a Corte, (a cura di Sandro Avanzo e Laura Bevione), Pisa, Titivillus Mostre Editore, pp. 29-34. 